\title{
Research on the Degree of Coupling between the Urban Public Infrastructure System and the Urban Economic, Social, and Environmental System: A Case Study in Beijing, China
}

\author{
ZhiMei Tao ${ }^{1,2}$ \\ ${ }^{1}$ College of Management and Economics, Tianjin University, Tianjin 300072, China \\ ${ }^{2}$ School of Public Administration, Tianjin University of Commerce, Tianjin 300134, China \\ Correspondence should be addressed to ZhiMei Tao; 499626452@qq.com
}

Received 25 January 2019; Revised 26 August 2019; Accepted 31 August 2019; Published 25 September 2019

Academic Editor: Konstantinos Karamanos

Copyright (c) 2019 ZhiMei Tao. This is an open access article distributed under the Creative Commons Attribution License, which permits unrestricted use, distribution, and reproduction in any medium, provided the original work is properly cited.

\begin{abstract}
The coordinated development of urban public infrastructure system and urban economic, social, and environmental system is an important goal for the integrated management and sustainable development of urban public infrastructure system. This paper constructs a research model of the degree of coupling coordination between urban public infrastructure system and urban economic, social, and environmental system using the analytic network process (ANP), the analytic hierarchy process (AHP), a combination evaluation method based on game theory, and a coupling coordination degree model. Using Beijing data from 2000 to 2016, the degree of coupling coordination between the Beijing urban public infrastructure system and the urban economic, social, and environmental system is empirically analyzed. This study finds that (1) the supply level of Beijing's urban public infrastructure system has an obvious impact on the degree of coupling coordination between the two systems. (2) The global financial crisis reduced the supply speed of the urban public infrastructure system in Beijing, and put the dynamic coupling state of the two systems in the low-level symbiosis stage. Beijing needs to improve the supply of urban public infrastructure to support the development of the urban economic, social, and environmental system. (3) Improving the supply level of the urban environmental infrastructure in Beijing, especially improving sewage disposal capacity and increasing the number of special vehicles for urban sanitation and the amount of domestic waste clearance, will positively affect the degree of coupling coordination between two systems. (4) An increase in the GDP of Beijing has a direct positive impact on the degree of coupling coordination. In addition, the increase in the social development level of the employees in three industries in Beijing has a significant impact on the degree of coupling coordination.
\end{abstract}

\section{Introduction}

An infrastructure system consisting of subsystems such as energy, transportation, water resources, postal service and telecommunication, and environmental facilities is an important basis for economic productivity and population welfare [1]. As a supporting system and carrier of urban economic and social activities, urban infrastructure supply faces a series of pressures and challenges under global urbanization. Due to a wide range of economic, social, technological, and other factors, the demand for urban infrastructure is gradually increasing, and many investments have been made to meet the needs of urban public infrastructure. Since 1981, China's fixed asset investment in urban public infrastructure has continued to increase, and its supply and service levels have continued to improve over the long term [2]. Nevertheless, the supply level of urban infrastructure still fails to meet social demand in China. After summer rainstorms, the drainage in cities is not adequate, and in the summer, "going to the city to see the sea" has become a phenomenon in many cities. Some cities are besieged by garbage; in some places, garbage is blown by the wind and sewage is evaporated, and other problems such as road zippers, traffic congestion, air 
and water pollution still exist. Improving the supply efficiency of urban infrastructure systems is an important problem for urban managers.

The urban public infrastructure system is a multibody, complex, and composite system of energy, transportation, postal services and telecommunications, the environment, water resources, and other subsystems. These subsystems are interdependent and interrelated and form the whole urban public infrastructure system together, providing the basic products and services needed for urban development $[3,4]$. Infrastructure supply is affected by the human research view and the specialized division of urban public infrastructure supply, and traditionally, which is provided by each department alone, there is a lack of communication and contact between departments $[3,5,6]$. Over time, people have become increasingly aware that the various subsystems of urban public infrastructure are interrelated and interact, forming a system of urban public infrastructure. Only by including supply management in the system as a whole can we improve the overall supply level of urban public infrastructure in an orderly manner, so that the urban public infrastructure system can meet the needs of urban economic and social development. The United Kingdom proposed studying the relationship between the national infrastructure system and economic and social development and managing the future development plan of the national infrastructure system as a whole [7]. In 2017, China's "13th Five-Year Plan for Urban Public Infrastructure Construction" propose for the first time to change the way in which previous departments compiled industry plans separately, to consider the overall planning of urban infrastructure in a systematic way and to coordinate the supply of products and services in all sectors to meet the requirements of urban economic and social development.

Understanding the interdependence of the various subsystems of urban public infrastructure is a prerequisite for studying the overall supply of urban public infrastructure systems. Different scholars define and classify the interdependence among subsystems of urban public infrastructure. Rinaldi believes that thee physical, information, spatial, and logical interdependence exists among the subsystems of urban public infrastructure [3]. Many scholars have summarized, classified, and simulated the interdependence of urban public infrastructure [8-10]. Jaime presents a System Safety Management System (SSMS) model to interdependency modelling for the case of the Mexico City Metro transport network, which highlights that interdependency in the Metro transportation network occurs vertically and horizontally [11]. The study of the interdependence of urban public infrastructure mainly focuses on the impact of urban public infrastructure interdependence when a sudden event occurs [12]. However, the interdependence of urban public infrastructure exists not only when an emergency arises but also in people's daily lives, and the impact on the supply of urban public infrastructure products and services is equally important [13]. The research on the interdependence of the various subsystems of urban public infrastructure has been deepening. Tao proposes that the indispensability, completeness, and irreplaceability of the subsystems of urban public infrastructure are the essence and fundamental reasons for the interdependence of the subsystems of urban public infrastructure and an important basis for the formation of the overall supply management system of urban infrastructure. The interdependence of the various subsystems of urban public infrastructure is of great significance to the normal operation of urban public infrastructure and the integrated supply management of the system [4]. Due to the complexity of the interdependence of urban infrastructure systems and their subsystems, studying the role of interdependence of infrastructure systems and the supply management of infrastructure systems is challenging [14].

The urban public infrastructure system should promote the city's economic growth, social welfare, and environmental quality development. An improvement in the supply level of urban public infrastructure systems will increase the labor productivity of the society, expand total social demand, increase the accumulation of fixed capital, increase the total output of the society, and guarantee the economic growth of the city $[15,16]$. In addition, an increase in the supply level of urban public infrastructure will promote the convenience of urban production and living activities, attract foreign populations, increase employment opportunities, and improve the social welfare level of cities $[17,18]$. The advancement of urbanization has put pressure on the urban environment to a certain extent. Urban public infrastructure can deal with urban garbage and sewage, reduce air pollution, slow the heat island effect, improve urban climate conditions, etc., and have a positive impact on the urban environment [19-21]. On the one hand, an improvement in the urban public infrastructure supply level will increase the level of urban development and the growth of urban social wealth so that the city government will be stronger and have more funds to invest in the construction and operation of urban infrastructure. On the other hand, due to the advancement of urbanization, urban population concentration, economic growth, and environmental quality have put pressure on urban public infrastructure. Urban public infrastructure is interdependent and mutually influential. An urban public infrastructure system based on interdependence is a collection of human activities that actively arrange and integrate the physical facilities and activities of the subsystems of urban public infrastructure and ensure that the subsystems of the urban public infrastructure interact to improve the overall efficiency of the urban public infrastructure system. Through infrastructure management control, the collection of information regarding system infrastructure demand, a consideration of the interdependence between the subsystems of infrastructure, expert opinion and government decision-making, city governments engage in urban infrastructure supply management and make decisions to ensure the supply of urban public infrastructure system can meet to support the development of urban, economic, social, and environmental system. The interaction that occurs between urban public infrastructure systems and 
urban economic and social environmental systems is shown in Figure 1. The direct goal of coordinated development between urban public infrastructure system and urban economic, social, and environmental system is to realize the integrated management of the supply benefits of urban public infrastructure systems, to improve the economic growth, social welfare, and environmental quality of cities. The long-term goal of the coordinated development of urban public infrastructure systems and urban economic, social, and environmental systems is to achieve the rational allocation of resources to urban public infrastructure systems and realize the long-term sustainable development of cities.

There is no research on the coordinated development of infrastructure and the economic environment in foreign countries. In the UK, the Infrastructure Transformation Research Consortium (ITRC), which consists of researchers from seven universities, including Oxford, Cambridge, Newcastle, and Leeds, proposes that urban infrastructure systems are complex applied systems [22]. Through the use of system-of-system modeling (SOSM), this consortium simulates and studies the relationship between national infrastructure and economic and social development and conducts cross-sectoral performance evaluations of infrastructure systems that face an uncertain future [7]. We compare research on the coordinated development of infrastructure and social development with SOSM research and find the following. follows:

The similarities between the two types of studies are as

(1) Both have comprehensive strategic objectives. The ultimate goal of both studies is to achieve sustainable regional or urban development through an orderly allocation of resources.

(2) Both have received considerable attention at the national level. In the UK, the national infrastructure system is highly regarded, while the national finance department proposes using an integrated approach to the development of national infrastructure plans [7]. China's Ministry of Construction proposes systematically studying the construction and management planning of urban public infrastructure and promoting solutions for urban problems.

(3) Both have a similar research objective: ITRC focuses on the long-term supply management of energy, transportation, water resources, solid waste and wastewater clean-up and recycling, and data and information communication services. The main research objective related to China's infrastructure and urban coordinated development is the relationship between the supply level of urban infrastructure systems and the level of urban development.

The differences between the two studies are as follows:

(1) Their research focus is different. SOSM proposes managing the infrastructure system across departments

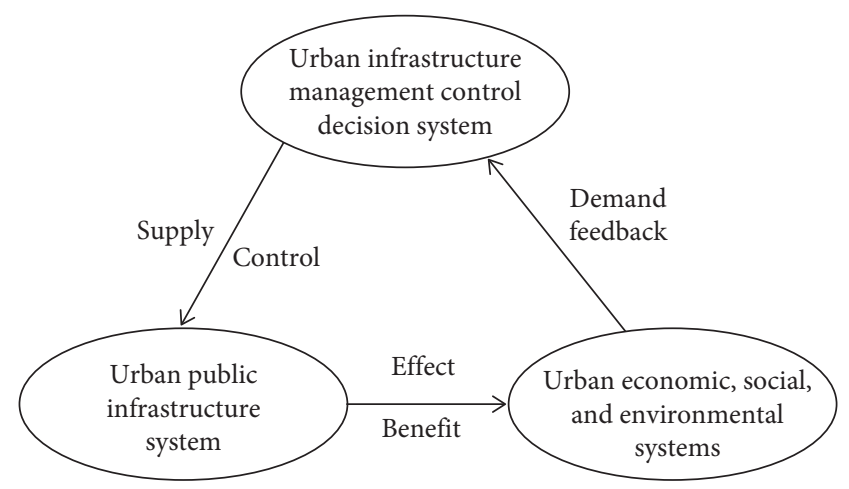

FIGURE 1: Interaction between urban public infrastructure supply and urban economic and social environment.

as a whole for the purpose of transforming, storing, and transmitting infrastructure traffic by managing physical infrastructure entities and the corresponding human system behaviors to allow for the long-term performance evaluation of the various departments involved in infrastructure. Research on the coordinated development of urban infrastructure and urban economic, social, and environmental systems considers the overall supply of urban public infrastructure and the given resources and their ability to support sustainable urban development, mainly by considering the overall management of the interaction between the supply level of infrastructure systems and the level of urban development.

(2) The scope of each type of research is different. The scope of research conducted using SOSM is limited to the UK's national infrastructure because the UK's infrastructure supply policy is made at the national level, and data on infrastructure supply, inputs, and outputs throughout the Commonwealth are available. Considering China's vast geographical scope and regional differences, China's research on the coordination of infrastructure and urban development mainly considers the synergistic relationship between the infrastructure provided by cities or regions and their jurisdiction and the development level of the cities or regions. Generally, coordinated development studies are not conducted at the national level.

(3) The perspective of each type of research is different. The research framework of SOSM combines topdown infrastructure supply management with bottom-up infrastructure providers and the behavioral performance of service objects based on the quality of service of the infrastructure (such as reliability, cost, security, and environmental impact) and focuses on the long-term management of national infrastructure through the linkage and management of a large number of infrastructure service departments. Coordinated development research generally does not consider subjective demand and differences in infrastructure service 
objects. This research mainly examines the level of urban public infrastructure supply by considering the number of services provided by urban infrastructure (e.g., electricity supply and garbage removal) and explores the interaction between infrastructure supply levels and the level of urban development.

(4) Each type of research has a different understanding of the interdependence of the infrastructure subsystems. SOSM is based on the premise that the interdependence of infrastructure subsystems is the basis for national infrastructure system integration modeling. It has been proposed that infrastructure involves more than the operation of a single specialized department. It is necessary to present the interdependence of various departments of the infrastructure using a cross-sectoral integration model and evaluate the cross-department performance of each subsystem of infrastructure. Existing research on urban coordinated development of infrastructure and the level of urban development does not recognize the interdependence of infrastructure subsystems and proposes that the urban public infrastructure system should support the level of urban development but not enforce an excessive level of urban development, which would waste social resources.

The earliest research on urban infrastructure and urban coordinated development was conducted by Zhang Junyong, who believes that urban infrastructure construction investment and economic development have a mutually reinforcing relationship [23]. At present, Chinese scholars' research on the coordinated development of infrastructure and cities is divided into two categories: qualitative research and quantitative research. Qualitative research focus on the sharing, co-construction, and coordinated development of environmental infrastructure [24], interact with each other on transportation infrastructure and urbanization [25]. Scholars who conduct quantitative research mainly include the following: $\mathrm{Yu}$ et al. [26] construct an index system to evaluate economic and social development and analyze the coordinated development of Qingdao's urban resources, infrastructure and economic society. Wu et al. [27]construct evaluation indicators for regional economic systems and calculate the coordination degree of the economic system and infrastructure system in various provinces and cities in China. Ying et al. [28] analyze the coordination of Hangzhou infrastructure and climate based on the coupling relationship between climate and green infrastructure.

In short, there is still a wide range of research fields that consider the coordinated development of domestic and foreign urban infrastructure supply and the level of urban development. (1) In terms of the evaluation index system, existing research is more focused on the coordinated development of the level of infrastructure supply and the level of urban development. This study incorporates indicators for the level of urban development measuring the environmental pressures in cities and constructs indicators for the urban economic, social, and environmental system by focusing on the three aspects of urban economic development, social welfare, and environmental pressure. This is a new breakthrough in the construction of an index system. (2) In terms of research methods, the methods used to generate the weights of the evaluation indicators are mainly limited to using the coupling coordination degree model. The dynamic coupling and coordination model has not been used. (3) In terms of the research design, this study focuses on the infrastructure system and the interdependence of the infrastructure subsystems. This study applies the network analytic hierarchy process (AHP) and considers the infrastructure of the interdependence of the subsystems to evaluate the supply level of the urban public infrastructure system.

This paper constructs a model of the coupling coordination degree of an urban infrastructure system and an urban economic, social, and environmental system using Beijing as an example. In addition, this paper provides a theoretical basis and discusses methods for ensuring the long-term and sustainable supply management of urban public infrastructure systems. The research design used in this paper is shown in Figure 2. The second part describes the research model used in this study, which involves AHP, ANP, the entropy method, a combination weight method based game theory, a coupling coordination degree model, and a dynamic coupling coordination degree model. The research model is used to evaluate the coordination of the urban public infrastructure system and the urban economic, social, and environmental system. The last part of this paper describes the empirical analysis of data on Beijing from 2000 to 2016 using the research model.

\section{Research Materials, Research Methods, and Model Construction}

\subsection{Research Materials}

2.1.1. Research Object. Beijing is the capital of China. It is the political, economic, and cultural center of the country and has advanced and comprehensive urban public infrastructure. In addition, data on Beijing's urban public infrastructure are abundant, typical, and representative. Research on the system integration supply management of Beijing's urban public infrastructure shows that it can be used as a model for other cities.

2.1.2. Evaluation Index System. To measure the relationship between the urban infrastructure system and the urban economic, social, and environmental system, this paper initially develops an index framework based on relevant references [26-30]. Then, according to the specific situation of Beijing and the principles of appropriateness, comparability, and availability, a final evaluation of the index system is conducted. The urban infrastructure 


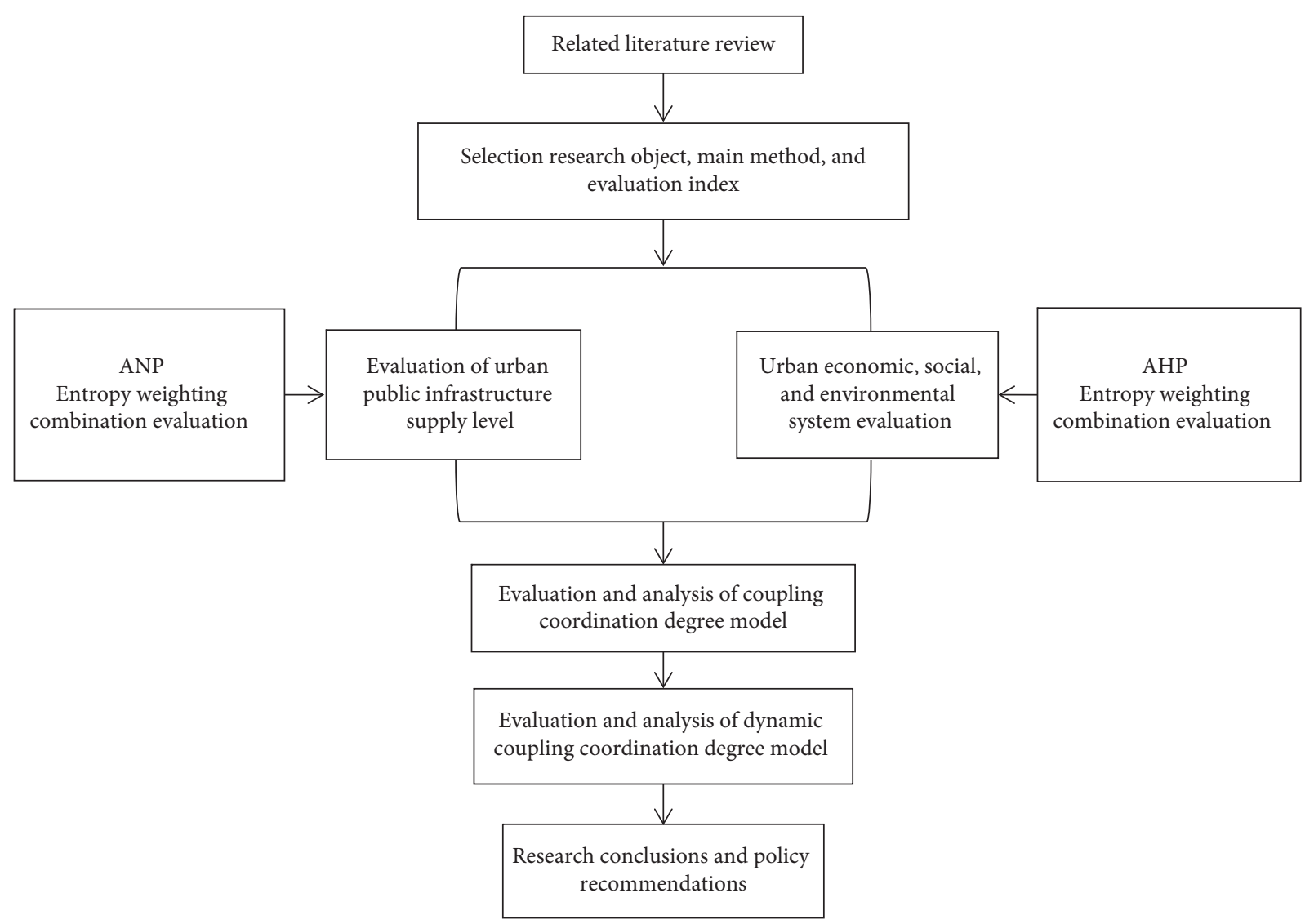

Figure 2: Research design flow chart.

system consists of five subsystems, energy, transportation, environment, water resources, postal services and telecommunications, as well as 20 evaluation indicators. The urban economic, social, and environmental system includes three subsystems, the urban economic, social and environmental subsystems, as well as 12 evaluation indicators. The final evaluation indicators are shown in Tables 1 and 2 .

\subsection{Research Method}

2.2.1. Preliminary Processing of Data. The relevant data on the supply level of various subsystems of Beijing's infrastructure and on the development level of Beijing's urban economic, social, and environmental system (2000-2016) were acquired from the Beijing Statistical Yearbook (Beijing Bureau of Statistics 2000-2016) through simple processing. All per capita indicators (including $I_{11}, I_{12}, I_{14}, I_{22}, I_{41}, I_{43}$, and $I_{51}$ ) represent the corresponding statistical data divided by the number of permanent residents in that year. All density indicators (including $I_{21}, I_{42}$, and $I_{44}$ ) represent the corresponding statistical data divided by the area of Beijing. The indicator $I_{21}$ is the sum of railway mileage and highway mileage divided by the area of Beijing. The data are standardized using formulas (1) and (2) (as shown in Tables 3 and 4).
Positive indicator:

$$
Y_{i j}=\frac{X_{i j}-\min \left\{X_{j}\right\}}{\max \left\{X_{j}\right\}-\min \left\{X_{j}\right\}}
$$

Negative indicator:

$$
Y_{i j}=\frac{\max \left\{X_{j}\right\}-X_{i j}}{\max \left\{X_{j}\right\}-\min \left\{X_{j}\right\}},
$$

where $X_{i j}$ represents the observed value of the $j$ th index in the $i$ th year; $\max \left\{X_{j}\right\}$ represents the maximum observation; $\min \left\{X_{j}\right\}$ represents the minimum observation; and $Y_{i j}$ is a standardized value.

\subsubsection{The ANP Is Used to Evaluate the Interdependence of the} Subsystems of Urban Public Infrastructure. The ANP is a multiobjective decision-making method developed by Professor Saaty $T \mathrm{~L}$ and is based on the $A H P$, which is especially applicable to complex system decision-making problems with internal interdependence and feedback from indicator elements [31]. The ANP method is used to evaluate the decisionmaking of the interdependence subsystem in the network to obtain weights of subsystem in the paper. 
TABLE 1: Evaluation indicators of the supply levels of the various subsystems of urban public infrastructure.

\begin{tabular}{|c|c|c|c|c|c|c|}
\hline Criteria layer & System layer & Indicator layer & Unit & $u_{\text {IEW }}$ & $u_{\mathrm{ANP}}$ & $u_{\mathrm{cW}}^{*}$ \\
\hline \multirow{4}{*}{$\begin{array}{l}\text { Economic } \\
\text { benefit }\end{array}$} & \multirow{4}{*}{$I_{1}$ : energy facilities system } & $\begin{array}{c}I_{11}: \text { per capita social electricity } \\
\text { consumption }\end{array}$ & $\begin{array}{l}\text { Kilowatt-hours/ } \\
\text { person }\end{array}$ & 0.0307 & 0.0294 & 0.0298 \\
\hline & & $I_{12}:$ per capita energy consumption & $\begin{array}{l}\text { tons of standard } \\
\text { coal/person }\end{array}$ & 0.0421 & 0.0664 & 0.0593 \\
\hline & & $I_{13}:$ natural gas ratio & & 0.0206 & 0.0157 & 0.0171 \\
\hline & & $I_{14}:$ per capita heating area & $\mathrm{m}^{2} /$ person & 0.0265 & 0.0114 & 0.0158 \\
\hline \multirow{4}{*}{ Social benefit } & \multirow{4}{*}{$I_{2}:$ road traffic system } & $\begin{array}{l}I_{21}: \text { railway and highway facilities } \\
\text { density }\end{array}$ & $\mathrm{km} / \mathrm{km}^{2}$ & 0.0586 & 0.1575 & 0.1287 \\
\hline & & $I_{22}:$ per capita urban road area & $\mathrm{m}^{2} /$ person & 0.0277 & 0.0241 & 0.0251 \\
\hline & & $\begin{array}{l}I_{23}: \text { number of public } \\
\text { transportation lines }\end{array}$ & Number & 0.0491 & 0.0442 & 0.0456 \\
\hline & & $\begin{array}{c}I_{24}: \text { bus operation passenger } \\
\text { volume }\end{array}$ & 10,000 persons & 0.0571 & 0.1011 & 0.0883 \\
\hline \multirow{12}{*}{$\begin{array}{l}\text { Environment } \\
\text { benefit }\end{array}$} & \multirow{4}{*}{$I_{3}:$ environmental protection system } & $I_{31}$ : per capita park green area & $\mathrm{m}^{2} /$ person & 0.0436 & 0.0580 & 0.0538 \\
\hline & & $\begin{array}{l}I_{32}: \text { sewage treatment capacity } \\
I_{33}: \text { total number of urban }\end{array}$ & $10,000 \mathrm{~m}^{3} /$ day & 0.0404 & 0.0302 & 0.0332 \\
\hline & & $\begin{array}{c}\text { sanitation special vehicle and } \\
\text { equipment }\end{array}$ & unit & 0.0335 & 0.0217 & 0.0251 \\
\hline & & $\begin{array}{c}I_{34} \text { : household garbage clearance } \\
\text { volume }\end{array}$ & 10,000 tons & 0.0519 & 0.0941 & 0.0818 \\
\hline & \multirow{3}{*}{$\begin{array}{l}I_{4}: \text { water resources and water supply } \\
\text { and drainage system }\end{array}$} & $I_{41}$ : per capita annual water supply & $\mathrm{m}^{3} /$ person & 0.1020 & 0.0957 & 0.0975 \\
\hline & & $I_{42}:$ density of piped water supply & $\mathrm{km} / \mathrm{km}^{2}$ & 0.0458 & 0.0590 & 0.0552 \\
\hline & & $\begin{array}{l}I_{43}: \text { per capita comprehensive } \\
\text { water production capacity }\end{array}$ & $\begin{array}{l}10 \text { thousand } \mathrm{m}^{3} / \\
\text { day person }\end{array}$ & 0.0400 & 0.0307 & 0.0334 \\
\hline & \multirow{5}{*}{. } & $I_{44}:$ sewage pipe density & $\mathrm{km} / \mathrm{km}^{2}$ & 0.0542 & 0.0221 & 0.0314 \\
\hline & & $\begin{array}{c}I_{51}: \text { per capita postal and } \\
\text { telecommunications volume }\end{array}$ & $\mathrm{CNY/person}$ & 0.0709 & 0.0864 & 0.0819 \\
\hline & & $I_{52}:$ mobile phone penetration rate & $\begin{array}{l}\text { Household } / 100 \\
\text { people }\end{array}$ & 0.0349 & 0.0151 & 0.0209 \\
\hline & & $I_{53}:$ mainline penetration rate & $\%$ & 0.0466 & 0.0088 & 0.0198 \\
\hline & & $\begin{array}{c}I_{54} \text { : bureau number of post and } \\
\text { telecommunications }\end{array}$ & Unit & 0.1238 & 0.0028 & 0.0380 \\
\hline
\end{tabular}

Note. The relevant data are from the Beijing Statistical Yearbook 2000-2016.

TABle 2: Urban economic social and environmental system evaluation indicators.

\begin{tabular}{|c|c|c|c|c|c|}
\hline Dimension layer & Indicator layer & Unit & $u_{\text {IEW }}$ & $u_{\mathrm{AHP}}$ & $u_{\mathrm{cW}}^{*}$ \\
\hline \multirow{4}{*}{$S_{1}:$ economic aspect } & $S_{11}:$ the actual value of gross domestic product & 100 million $\mathrm{CNY}$ & 0.0728 & 0.3365 & 0.2560 \\
\hline & $S_{12}:$ the proportion of the tertiary industry & $\%$ & 0.0646 & 0.0586 & 0.0604 \\
\hline & $S_{13}$ : actual utilization of foreign direct investment & 10,000 USD & 0.1349 & 0.0342 & 0.0649 \\
\hline & $S_{14}:$ fixed assets investment ratio & $\%$ & 0.0634 & 0.1103 & 0.0960 \\
\hline \multirow{4}{*}{$S_{2}$ : social aspect } & $S_{21}:$ per capita household disposable income & $\mathrm{CNY}$ & 0.1194 & 0.0580 & 0.0767 \\
\hline & $S_{22}:$ per capita consumption expenditure & $\mathrm{CNY}$ & 0.1197 & 0.0941 & 0.1019 \\
\hline & $S_{23}$ : number of employees in three industries & Person & 0.0757 & 0.0302 & 0.0441 \\
\hline & $S_{24}:$ urbanization rate & $\%$ & 0.0725 & 0.0217 & 0.0372 \\
\hline \multirow{4}{*}{$S_{3}$ : environmental aspects } & $S_{31}$ : annual average of inhalable particles & $\mathrm{mg} / \mathrm{m}^{3}$ & 0.0670 & 0.0078 & 0.0259 \\
\hline & $S_{32}:$ total wastewater discharge & 10 thousand tons & 0.1234 & 0.0766 & 0.0909 \\
\hline & $S_{33}$ : general industrial solid waste production & 10 thousand tons & 0.0375 & 0.0251 & 0.0289 \\
\hline & $S_{34}:$ sulfur dioxide emissions & 10 thousand tons & 0.0492 & 0.0133 & 0.0243 \\
\hline
\end{tabular}

Note. The relevant data are from the Beijing Statistical Yearbook 2000-2016.

2.2.3. The Weight of the Evaluation Index of Each Subsystem Is Obtained by Using a Combination Weighting Method Based on Game Theory. Game theory is an important part of operations research and is used for studying competitive elements. Drawing on game theory, relevant experts have developed a game theory combination weighting method $[32,33]$ that uses comprehensive subjective and objective weighting to overcome the limitations of subjective weighting and objective weighting. The paper uses a combined weight method based on game theory to calculate the weight of the evaluation indicators of the urban public infrastructure system and the urban economic social and environmental system.

The calculation process of combination weighting method based on game theory is as follows: 


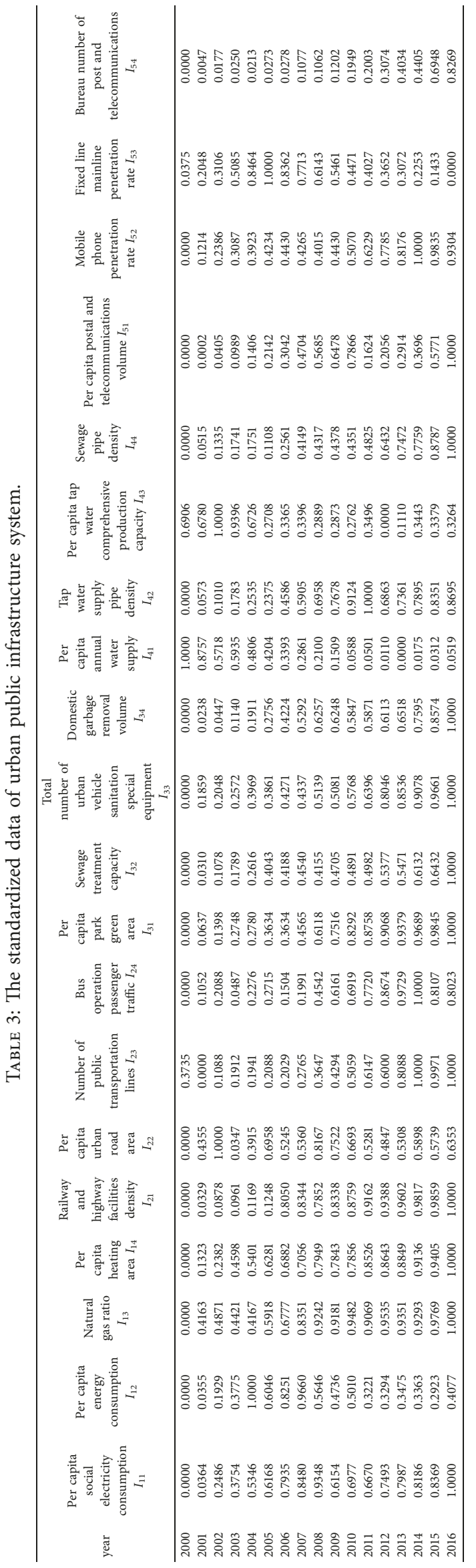




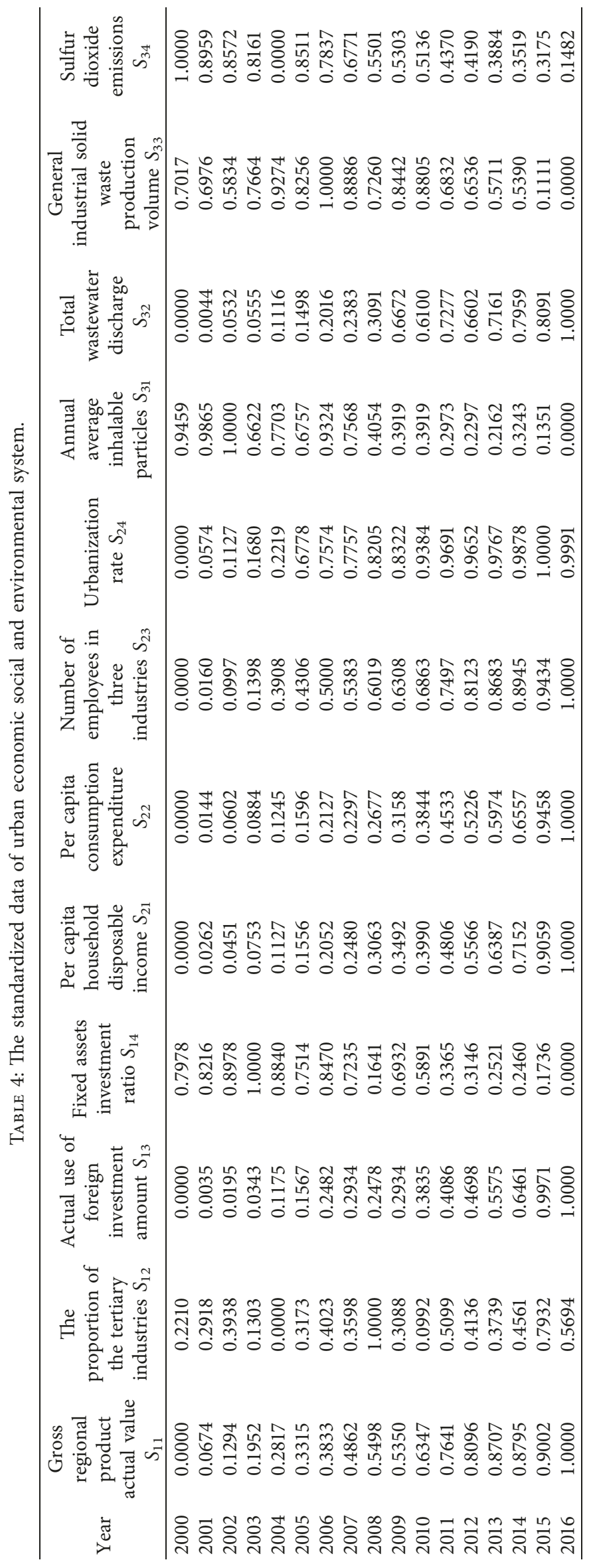


(1) Obtain $n$ weights according to the n-type weighting method, and then construct a basic weight vector set $U=\left\{u_{1}, u_{2}, \ldots, u_{n}\right\}$ These $n$ vectors are arbitrarily linearly combined to form a possible set of weights:

$$
U=\sum_{k=1}^{n} W_{k} u_{k}^{T}\left(w_{k} \geq 0\right),
$$

where $u$ is a possible weight vector of a possible set of weight vectors and $W_{k}$ is the weight coefficient.

We use game theory to find the most satisfactory $u^{*}$ in the possible vector set. The most satisfactory weight vector can be transformed by optimizing the linear combination weight coefficient $W_{k}$. The goal of optimization is to minimize the dispersion of $u$ from each $u_{k}$. That is,

$$
\min \left\|\sum_{j=1}^{n} w_{j} \times u_{j}^{T}-u_{j}^{T}\right\|_{2}, \quad(i=1,2, \ldots, n) .
$$

Based on the differential properties of the matrix, the first derivative condition of the optimization of equation (4) is

$$
\sum_{j=1}^{n} W_{j} \times u_{j} \times u_{j}^{T}=u_{i} \times u_{j}^{T}, \quad(i=1,2, \ldots, n) .
$$

Equation (5) corresponds to a linear system of equations:

$$
\left[\begin{array}{cccc}
u_{1} \cdot u_{1}^{T} & u_{1} \cdot u_{2}^{T} & \ldots & u_{1} \cdot u_{n}^{T} \\
u_{2} \cdot u_{1}^{T} & u_{2} \cdot u_{2}^{T} & \ldots & u_{2} \cdot u_{n}^{T} \\
\cdots & \ldots & \ldots & \ldots \\
u_{n} \cdot u_{1}^{T} & u_{n} \cdot u_{2}^{T} & \ldots & u_{n} \cdot u_{n}^{T}
\end{array}\right]\left[\begin{array}{c}
w_{1} \\
w_{2} \\
\ldots \\
w_{n}
\end{array}\right]=\left[\begin{array}{c}
u_{1} \cdot u_{1}^{T} \\
u_{1} \cdot u_{2}^{T} \\
\cdots \\
u_{n} \cdot u_{n}^{T}
\end{array}\right] .
$$

After obtaining $\left(w_{1}, w_{2}, \ldots, w_{n}\right)$ using formula (6), we normalize it:

$$
W_{k}^{*}=\frac{w_{k}}{\sum_{k=1}^{n} w_{k}} .
$$

Finally, the combined weight is

$$
u^{*}=\sum_{k=1}^{n} w_{k} u_{k}^{T}
$$

\subsection{Research Model Construction}

2.3.1. Model Used to Evaluate the Supply Level of the Urban Public Infrastructure System. The model used to evaluate the supply level of the urban public infrastructure system (see Figure 3 ) is divided into three levels. The first level is the rule layer, which includes three aspects: economic growth, social welfare, and environmental pressure on urban public infrastructure systems. The second layer of the model is the network layer. Considering the purpose of the research, five subsystems of the public infrastructure system are included in the model, namely, water resources and water supply and drainage system $\left(I_{1}\right)$, transportation system $\left(I_{2}\right)$, postal power system $\left(I_{3}\right)$, environmental facilities system $\left(I_{4}\right)$, and energy facilities system $\left(I_{5}\right)$, which are consistent with Table 1 . The third layer of the model is the system indicator layer, which consists of the evaluation indicators for the supply level of each subsystem.

The main process used to evaluate the supply level of the urban public infrastructure system is described below:

Step 1. According to the urban development orientation, the established stock of the urban public infrastructure and the interdependence of the public infrastructure determine the structural relationship of the urban public infrastructure system and act as the basis for constructing the structure of the urban public infrastructure system ANP management activities. This process needs to be conducted by experts.

Step 2. The ANP super matrix and the weighted super matrix are calculated. The evaluation criteria used for the ANP act as the basis for evaluating the relationships in the system and reflect the overall goal of the evaluation. Let the evaluation criteria in the ANP structure be $C_{i}, i=1,2, \ldots, m$. The system's network layer has subsystems $\mathrm{I}_{j}, j=1,2, \ldots, n$. For evaluating the supply level of urban public infrastructure systems and interdependence, $C_{i}$ is used as a criterion to judge the interdependence of urban public infrastructure subsystems. On this basis, the judgment matrix is constructed to form the feature vector $\left(W_{1 j}, W_{2 j}, \ldots, W_{i j}\right)$. When the feature vector passes the consistency test, it is expressed as a matrix form, and a local weight vector matrix $W_{i j}$ is generated. $m$ supermatrices $W$ are formed under the influence of the control criterion index $C_{i}$; however, $W$ is not a normalized matrix. To ensure the calculation results are objective and comparable, the supermatrix columns are normalized. The corresponding weighting factor $Y_{i j}, i, j=1,2,3, \ldots, n$ is set, and the superweighted matrix is $\overline{W_{i j}}=y_{i j} w_{i j}$.

To accurately reflect the interaction between the subsystems, the stability of the supermatrix must be processed. Stability processing is performed on the superweighting matrix $\bar{W}_{i j}$, generating an ANP limit matrix $W^{\infty}$. The processing method is as follows:

$$
W^{\infty}=\lim _{k=\longrightarrow \infty}\left(\frac{1}{m}\right) \sum_{i=1}^{m} \bar{W}^{k} .
$$

Equation (9) is convergent and unique, and the value of the corresponding column in the original matrix is the weight of the stability of the urban public infrastructure subsystem.

Step 3. After the subsystem weights are obtained, the weights of the internal indicators of each subsystem are obtained using AHP.

Step 4. The entropy method is used to obtain the evaluation index weight of each subsystem $[34,35]$.

Step 5. Using a combination weighting method based on game theory, the weights of the evaluation indexes of each subsystem are obtained. 


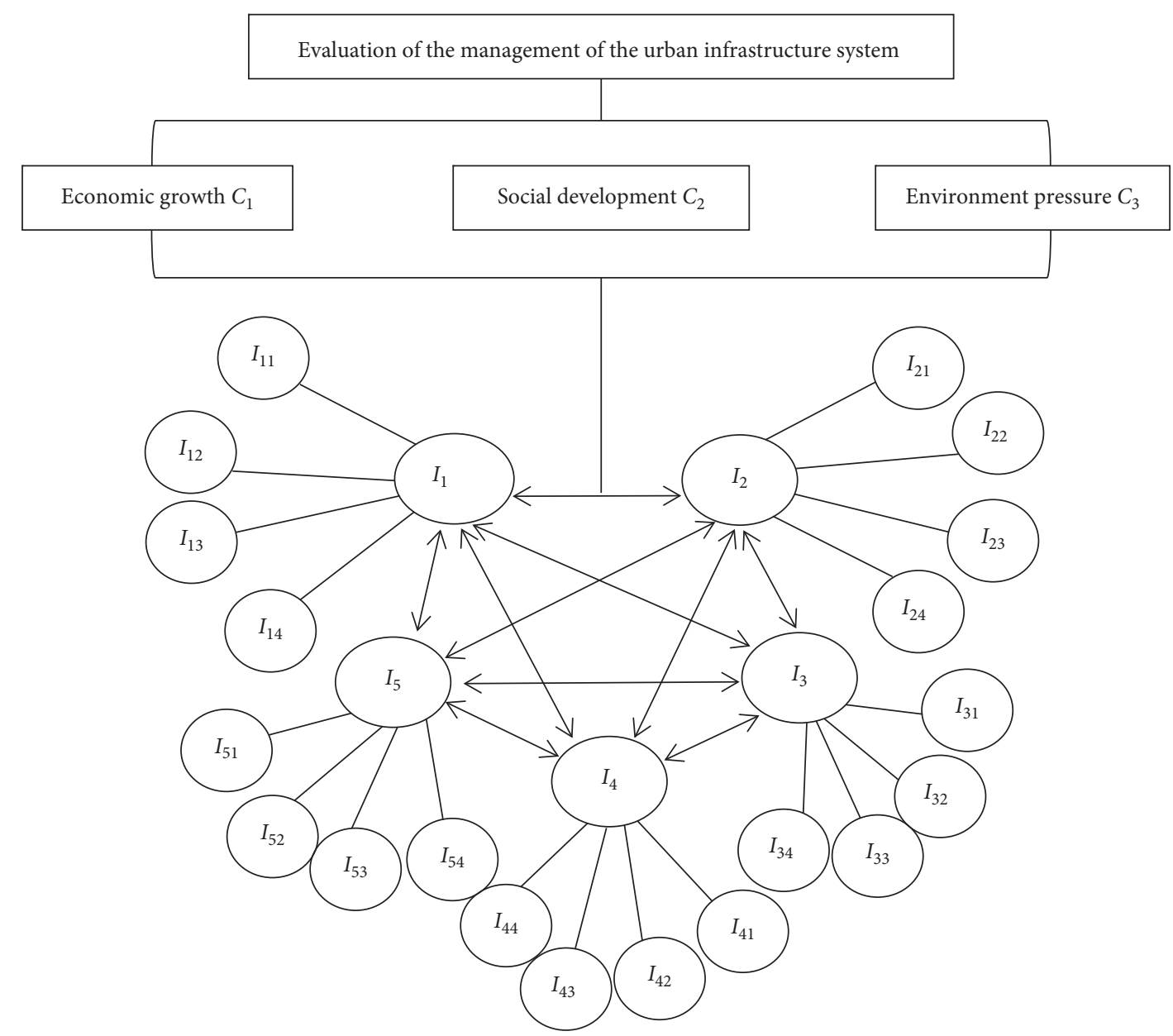

FIgURE 3: Model used to evaluate the management of the supply level of the urban public infrastructure system.

Step 6. The supply level of each subsystem and the overall system are obtained.

The supply level of each subsystem and the system supply level are obtained by using index weights are calculated using a combination weighting method based on game theory.

$$
S_{\text {subsystem }, i, r}=\sum_{j=1}^{n} u_{j r}^{*} Y_{i j},
$$

where $S_{\text {subsystem,i,r }}$ represents the supply level of each subsystem; $1,2, \ldots, 5$ represent 5 different subsystems; $i$ represents the year; and $u_{j r}^{*}$ represents the weight of the combination index (which is based on game theory) for each subsystem.

The supply level of the urban public infrastructure system is obtained by using the following formula:

$$
S_{\text {system }, i}=\sum_{j=1}^{n} u_{j}^{*} Y_{i j},
$$

where $u_{j r}^{*}$ represents the supply level of the urban public infrastructure system and $u^{*}$ represents the weight of the combination index (which is based on game theory) of the urban public infrastructure system.

\subsubsection{Coupling Coordination Analysis}

(1) Coupling Coordination Model (CCM). Coupling is a term used in physics to indicate the degree to which two or more systems interact and affect each other to reach a degree of synergy. Coupling is used to measure the degree of agreement in terms of the level of system development. Liao was the first to develop a model to evaluate the degree of coupling coordination within a system or between different systems and further differentiated the levels of coupling coordination degree [36]. This paper constructs a CCM of the urban public infrastructure system and the urban economic social and environmental system to analyze the degree of coordinated development between the urban public infrastructure system and the level of urban development. The calculation process of the CCM is as follows:

(1) The evaluation value of the urban public infrastructure system and the urban economic, social, and environmental system is calculated, which are represented by $f(x)$ and $g(y)$, respectively. These are shown in Table 5.

(2) The coupling degree of the urban public infrastructure system and the urban economic social and environmental system is calculated: 
TABLE 5: Evaluation of the supply level of urban infrastructure system and the demand level of the urban economic, social, and environmental system.

\begin{tabular}{lcc}
\hline Years & Urban infrastructure system supply level $(f(x))$ & $\begin{array}{c}\text { Urban economic, social, and environmental system } \\
\text { evaluation value }(g(y))\end{array}$ \\
\hline 2000 & 0.1383 & 0.1590 \\
2001 & 0.1675 & 0.1882 \\
2002 & 0.2247 & 0.2310 \\
2003 & 0.2413 & 0.2474 \\
2004 & 0.3200 & 0.2683 \\
2005 & 0.3204 & 0.3344 \\
2006 & 0.4425 & 0.3979 \\
2007 & 0.5045 & 0.4131 \\
2008 & 0.5320 & 0.4138 \\
2009 & 0.5528 & 0.4670 \\
2010 & 0.5862 & 0.4884 \\
2011 & 0.5519 & 0.5416 \\
2012 & 0.5568 & 0.5556 \\
2013 & 0.6076 & 0.5870 \\
2014 & 0.6606 & 0.6210 \\
2015 & 0.6860 & 0.6924 \\
\hline
\end{tabular}

$$
\begin{aligned}
C & =\left\{\frac{f(x)^{*} g(y)}{((f(x)+g(y)) / 2)^{2}}\right\}^{1 / 2}, \\
T & =a f(x)+b g(y), \\
D(x, y) & =\sqrt{C \cdot T},
\end{aligned}
$$

where $D$ represents the degree of the coupling between the two systems, $D \in(0,1), C$ represents the degree of coordination between the two systems, $C \in(0,1)$, $T$ represents the comprehensive coordination index of the two systems, and $a$ and $b$ represent the contribution of the two systems. Let $f(x)$.

(2) Dynamic Coupling Coordination Model (DCCM). The DCCM is used to determine the coupling degree of the composite system [37]. Li and Ding was the first to propose a DCCM and used it to evaluate the coordination of resource environment systems and social economic systems and then calculated the coordination degree of the composite system [38].

To clarify the relationship between the urban public infrastructure system and the urban economic, social, and environmental system, this paper assumes that both of these systems and their relationship form a composite system. Based on theory of the evolution of subsystems in a general system, we construct a DCCM to analyze the evolution state and coupling state of the composite systems. The changes between the urban public infrastructure system and the urban economic, social, and environmental system are nonlinear, so the evolution equation can be expressed as

$$
\frac{d_{x}(t)}{d_{t}}=f\left(x_{1}, x_{2}, \ldots, x_{n}\right) ; \quad i=1,2, \ldots, n,
$$

where $f$ is a nonlinear function of $x_{i}$. The motion stability of a nonlinear system depends on the characteristic root property of the first approximation system. The high-order term can guarantee the stability of motion and be used to obtain an approximate linear system.

$$
\frac{d_{x}(t)}{d_{t}}=\sum_{i=1}^{n} a_{i} x_{i} ; \quad i=1,2, \ldots, n .
$$

Using the above method, we establish the general function of the urban public infrastructure system and the urban economic, social, and environmental system.

$$
\begin{aligned}
& f(x)=\sum_{i=1}^{n} a_{i} x_{i}^{*} ; \quad i=1,2, \ldots, n, \\
& g(y)=\sum_{i=1}^{n} b_{i} y_{i}^{*} ; \quad i=1,2, \ldots, n .
\end{aligned}
$$

We assume that the urban public infrastructure system and the urban economic, social, and environmental system and their relationship are in the same system, which has two elements $F(x)$ and $F(y)$. According to Beta Langfi's general system theory, the evolution equation of a composite system is expressed as

$$
\begin{aligned}
& F(x)=\frac{d_{f(x)}}{d_{t}}=T_{1} f(x)+T_{2} g(y), \\
& V_{F(x)}=\frac{d_{F(x)}}{d_{t}}, \\
& G(y)=\frac{d_{g(x)}}{d_{t}}=U_{1} f(x)+U_{2} g(y), \\
& V_{G(y)}=\frac{d_{G(y)}}{d_{t}} .
\end{aligned}
$$


$F(x)$ and $G(y)$ are the evolutionary states of the urban public infrastructure system and the urban economic, social, and environmental system under their own interaction and external conditions. $V_{F(x)}$ and $V_{G(y)}$ are the respective evolutionary speeds of the urban public infrastructure system and the urban economic, social, and environmental system. In a composite system, because the entire system contains only two elements $F(x)$ and $G(y)$, any changes in the subsystem that occur when $F(x)$ and $G(y)$ interact will cause the entire system to change. The evolution rate $V$ of a composite system can be seen as a function of $V_{F(x)}$ and $V_{G(y)}$, so $V_{G(y)}$. Therefore, $V_{F(x)}$ and $V_{G(y)}$ are used as control variables; the coupling relationship between the composite system and the two subsystems can be obtained by studying the variation in $V$. Because the evolution of the entire system satisfies the $S$-type development mechanism, we assume that the dynamic coupling and coordination relationship between the urban public infrastructure system and the urban economic, social, and environmental system is cyclical. Since a change in $V$ is caused by $V_{F(x)}$ and $V_{G(y)}$, we analyze $V$ on the two-dimensional coordinate plane $\left(V_{F(x)}\right.$, $\left.V_{G(y)}\right)$. The change in $V$ is an ellipse in the coordinate system (the change in the urban economic, social, and environmental system is not as rapid as that of the urban public infrastructure system, and the amplitude is relatively small), as shown in Figure 4.

In this case, the variable $V$ is an ellipse. The variable $\beta$ represents the angle between $V_{F(x)}$ and $V_{G(y)}$. According to the value of $\beta$, we can determine the value of the dynamic coupling coordination degree of the composite system. Based on relevant research [38], this paper proposes the development stage and state of the dynamic coupling coordination degree of the composite system, as shown in Table 6.

$$
\beta=\arctan \left(\frac{V_{F(x)}}{V_{G(y)}}\right) .
$$

\section{Empirical Research}

\subsection{Calculation of the Evaluation Value of the Supply Level of the Urban Public Infrastructure System}

3.1.1. ANP Analysis of the Supply Weights of the Urban Public Infrastructure Subsystem. Under the constraints of the comprehensive development level of the economic, social, and environmental subsystems in cities, this paper uses Super Decisions software to evaluate the supply level of the urban public infrastructure. Taking into account the strong professionalism of the research questions, this paper selects eight experts, including senior management personnel and senior engineers, who have 10-20 years of experience in the urban public infrastructure field, to score the judgment matrix reflecting the supply structure management of the urban public infrastructure system. The experts evaluated based on a comparison of contribution rates, the principle of the universality rate and the principle of irreplaceability. The results are shown in Tables 7-14.

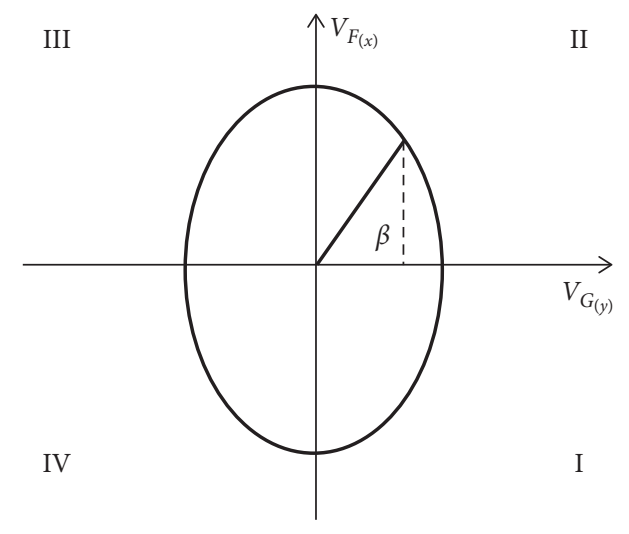

Figure 4: Dynamic coupling degree between urban public infrastructure and the urban economic, social, and environmental system (created by author based on Li Chongming's study [38]).

In the ANP model of the overall supply level of the urban public infrastructure system, evaluation criteria for economic growth $\left(C_{1}\right)$, social welfare $\left(C_{2}\right)$, and environmental pressure $\left(C_{3}\right)$ evaluation criteria are used to identify the interactions among the subsystems of urban public infrastructure in the network layer, and the corresponding judgment matrix is established, as shown in the table below. The relationship between the judgment indicators in the table is based on a 9-point method; 1-9 indicates that the influence of one subsystem on the other subsystem has gradually increased. The score of the judgment matrix is taken as the mean of the expert score. The consistency test result of the judgment matrix is $0.056(<0.1)$, indicating that the judgment matrix passes the consistency test.

When all the judgment matrices pass the consistency test, the ANP supermatrix, the weighted supermatrix, and the limit matrix of the urban public infrastructure system supply level evaluation model are generated using Super Decisions software. Since the limits in the limit matrix converge and are unique, the weights of the interdependent subsystems in the model of the supply level of urban public infrastructure are obtained, which is $W_{i}=(0.5396,0.2970$, $0.1634)$. The weights of the subsystems in the network layer are $(0.2075,0.3270,0.1386,0.2040$, and 0.1229$)$.

3.1.2. Entropy Method. Through the collection, processing, and standardization of the statistical yearbook data used in the evaluation indexes of the five subsystems in Beijing, the entropy weight of the evaluation index is calculated using the entropy method (see Table 1).

3.1.3. The Weights in Each Indicator System Are Calculated Using a Combined Weight Method Based on Game Theory. The weight of the evaluation index of each subsystem obtained by the entropy method is $u_{\text {IEW }}$. The weight of the evaluation index obtained by the ANP method is $u_{\text {ANP. }}$ Using the combined weight method based on game theory combined with the objective evaluation of the entropy method and the subjective evaluation of ANP, the weight of 
TABLE 6: Dynamic coupling and coordination of the composite system.

\begin{tabular}{|c|c|c|c|}
\hline Range of $\beta$ & Stage & System development stage & System status \\
\hline$-90^{\circ}<\beta \leq 0^{\circ}$ & I & Low-level symbiosis & $\begin{array}{l}\text { At this stage of development, the development speed } \\
\text { of urban public infrastructure systems is very low, } \\
\text { and the impact of urban public infrastructure systems } \\
\text { on urban economic, social, and environmental } \\
\text { systems is almost } 0 .\end{array}$ \\
\hline $0^{\circ} \prec \beta \prec 45^{\circ}$ & II & Primary coordinated development stage & $\begin{array}{l}V_{F(x)}<V_{G(y)} \text { The development speed of urban public } \\
\text { infrastructure system is lower than that of urban } \\
\text { economic, social, and environmental system. Urban } \\
\text { public infrastructure system can not promote the } \\
\text { development of urban economic, social, and } \\
\text { environmental system, showing that urban } \\
\text { infrastructure system can not carry the development } \\
\text { of urban economic, social, and environmental } \\
\text { system. }\end{array}$ \\
\hline$\beta=45^{\circ}$ & & Coordinated development stage & $\begin{array}{l}\qquad V_{F(x)}=V_{G(y)} \text { The speed of urban public } \\
\text { infrastructure system is equal to the urban economic, } \\
\text { social, and environmental system, and the urban } \\
\text { public infrastructure system and the urban economic, } \\
\text { social, and environmental system are coordinated. }\end{array}$ \\
\hline $45^{\circ} \prec \beta \leq 90^{\circ}$ & & Coordinated development stage & $\begin{array}{l}V_{F(x)}>V_{G(y)} \text { With the development of the urban } \\
\text { public infrastructure system, the two systems began } \\
\text { to interact with each other. The restrictions of the } \\
\text { urban economic, social, and environmental system } \\
\text { on the urban public infrastructure system began to } \\
\text { appear, but it was not obvious. }\end{array}$ \\
\hline $90^{\circ}<\beta \leq 180^{\circ}$ & III & Extreme development stage & $\begin{array}{l}\text { With the accelerated development of urban } \\
\text { economic, social, and environmental systems, urban } \\
\text { public infrastructure systems have increased the } \\
\text { demand for urban development, and the } \\
\text { contradiction between infrastructure systems and } \\
\text { urban systems has emerged, and began to limit the } \\
\text { improvement of urban development level. }\end{array}$ \\
\hline$-180^{\circ}<\beta \leq-90^{\circ}$ & IV & High-level coordinated development stage & $\begin{array}{l}\text { The composite system gradually transforms into a } \\
\text { common development stage, and finally reaches the } \\
\text { high-level coordinated development of the urban } \\
\text { public infrastructure system and the urban economic, } \\
\text { social, and environmental system }\end{array}$ \\
\hline
\end{tabular}

The authors edited the table by themselves according to Li Chongming's literature [38].

TABLE 7: ANP judgment matrix of the system (based on $C_{1}$ ).

\begin{tabular}{cccccc}
\hline & $I_{1}$ & $I_{2}$ & $I_{3}$ & $I_{4}$ & $I_{5}$ \\
\hline$I_{1}$ & 1 & $1 / 2$ & 2 & 5 & 3 \\
$I_{2}$ & 2 & 1 & 3 & 6 & 4 \\
$I_{3}$ & $1 / 2$ & $1 / 3$ & 1 & 4 & 2 \\
$I_{4}$ & $1 / 5$ & $1 / 6$ & $1 / 4$ & 1 & $1 / 3$ \\
$I_{5}$ & $1 / 3$ & $1 / 4$ & $1 / 2$ & 3 & 1 \\
\hline
\end{tabular}

the optimal urban public infrastructure evaluation index is expressed as $u_{\mathrm{cw}}^{*}$ (as shown in Table 1).

3.1.4. The Evaluation Value of the Supply Level of the Typical Urban Public Infrastructure System Is Obtained. The evaluation value of the urban infrastructure system supply level is obtained by using equation (11) (Table 5). The evaluation value of the urban infrastructure system from 2000 to 2016 gradually increased the supply level of the urban
TABLE 8: ANP judgment matrix of the system (based on $C_{2}$ ).

\begin{tabular}{cccccc}
\hline & $I_{1}$ & $I_{2}$ & $I_{3}$ & $I_{4}$ & $I_{5}$ \\
\hline$I_{1}$ & 1 & $1 / 2$ & 2 & 5 & 3 \\
$I_{2}$ & 2 & 1 & 3 & 6 & 4 \\
$I_{3}$ & $1 / 2$ & $1 / 3$ & 1 & 4 & 2 \\
$I_{4}$ & $1 / 5$ & $1 / 6$ & $1 / 4$ & 1 & $1 / 3$ \\
$I_{5}$ & $1 / 3$ & $1 / 4$ & $1 / 2$ & 3 & 1 \\
\hline
\end{tabular}

infrastructure systems from 0.1383 to 0.6372 , with a growth rate of $78.3 \%$.

3.2. Calculation of the Evaluation Value of the Urban Economic, Social, and Environmental System. Using the entropy method and the AHP method on the urban economic, social, and environmental system indicators shown in Table 2, the index weights are obtained by using a combined weight method based on game theory. Then, the evaluation value of the demand level of the economic, social, and environmental 
TABLE 9: ANP judgment matrix of the system (based on $C_{3}$ ).

\begin{tabular}{lcccc}
\hline$I_{1}$ & $I_{2}$ & $I_{3}$ & $I_{4}$ & $I_{5}$ \\
\hline 1 & 2 & $1 / 2$ & 3 & 5 \\
$1 / 2$ & 1 & $1 / 3$ & 2 & 4 \\
2 & 3 & 1 & 4 & 7 \\
$1 / 3$ & $1 / 2$ & $1 / 4$ & 1 & 3 \\
$1 / 5$ & $1 / 4$ & $1 / 7$ & $1 / 3$ & 1 \\
\hline
\end{tabular}

TABLE 10: ANP judgment matrix of the system (based on $I_{1}$ ).

\begin{tabular}{ccccc}
\hline & $I_{2}$ & $I_{3}$ & $I_{4}$ & $I_{5}$ \\
\hline$I_{2}$ & 1 & 4 & 2 & 6 \\
$I_{3}$ & $1 / 4$ & 1 & $1 / 2$ & 3 \\
$I_{4}$ & $1 / 2$ & 2 & 1 & 5 \\
$I_{5}$ & $1 / 6$ & $1 / 3$ & $1 / 5$ & 1 \\
\hline
\end{tabular}

TABLe 11: ANP judgment matrix of the system (based on $I_{2}$ ).

\begin{tabular}{ccccc}
\hline & $I_{1}$ & $I_{3}$ & $I_{4}$ & $I_{5}$ \\
\hline$I_{1}$ & 1 & 3 & 2 & 5 \\
$I_{3}$ & $1 / 3$ & 1 & $1 / 2$ & 3 \\
$I_{4}$ & $1 / 2$ & 2 & 1 & 4 \\
$I_{5}$ & $1 / 5$ & $1 / 3$ & $1 / 4$ & 1 \\
\hline
\end{tabular}

TABLE 12: ANP judgment matrix of the system (based on $I_{3}$ ).

\begin{tabular}{ccccc}
\hline & $I_{1}$ & $I_{2}$ & $I_{4}$ & $I_{5}$ \\
\hline$I_{1}$ & 1 & $1 / 2$ & 1 & 3 \\
$I_{2}$ & 2 & 1 & 2 & 4 \\
$I_{4}$ & 1 & $1 / 2$ & 1 & 3 \\
$I_{5}$ & $1 / 3$ & $1 / 4$ & $1 / 3$ & 1 \\
\hline
\end{tabular}

TABLE 13: ANP judgment matrix of the system (based on $I_{4}$ ).

\begin{tabular}{ccccc}
\hline & $I_{1}$ & $I_{2}$ & $I_{3}$ & $I_{5}$ \\
\hline$I_{1}$ & 1 & $1 / 2$ & 3 & 5 \\
$I_{2}$ & 2 & 1 & 4 & 6 \\
$I_{3}$ & $1 / 3$ & $1 / 4$ & 1 & 3 \\
$I_{5}$ & $1 / 5$ & $1 / 6$ & $1 / 3$ & 1 \\
\hline
\end{tabular}

TABLE 14: ANP judgment matrix of the system (based on $I_{5}$ ).

\begin{tabular}{ccccc}
\hline & $I_{1}$ & $I_{2}$ & $I_{3}$ & $I_{4}$ \\
\hline$I_{1}$ & 1 & $1 / 2$ & 3 & 5 \\
$I_{2}$ & 2 & 1 & 4 & 7 \\
$I_{3}$ & $1 / 3$ & $1 / 4$ & 1 & 3 \\
$I_{4}$ & $1 / 5$ & $1 / 7$ & $1 / 3$ & 1 \\
\hline
\end{tabular}

system in Beijing is obtained (Table 5). The demand level of the urban economic, social, and environmental system has gradually increased from 2000 to 2016, from 0.1590 to 0.7097 , with a growth rate of $77.6 \%$.

The time series of the evaluation values of the supply level of the urban public infrastructure system and the demand level of the urban economic, social, and environmental system from 2000 to 2016 can be divided into four stages. The evaluation value of the urban public infrastructure system from 2000 to 2005 is very close to the demand level of the urban economic, social, and environmental system. From 2006 to 2011, the supply level of the urban infrastructure system is greater than the demand level of the urban economic, social, and environmental system. From 2011 to 2015, the supply level of the urban public infrastructure system is close to the evaluation level of the demand level of the urban economic, social, and environmental system. In 2016, the demand level of the urban economic, social, and environmental system is greater than the supply level of the urban public infrastructure system. During the 11th Five-Year Plan period, the average annual growth rate of urban infrastructure fixed asset investment reached $27 \%$, which is much higher than $7.29 \%$ in the 15th period and $7.35 \%$ in the 12th Five-Year Plan period. As a result of the global financial crisis, Beijing's GDP had negative growth in 2009, which explains why the supply of the urban public infrastructure system from 2006 to 2010 is higher than the demand for the urban economic, social, and environmental system.

\subsection{Analysis of the Coupling Degree of the Level of Supply of the} Urban Public Infrastructure System and the Urban Economic, Social, and Environmental System. Table 15 shows that the degree of coordination between the urban public infrastructure system and the urban economic, social, and environmental system increases from 0.9976 to 0.9986 from 2000 to 2016, and the change is relatively stable. However, the coupling coordination degree $D$ increases from 0.3851 to 0.8200 , and a significant change occurs. The third column of Table 15 shows that the coupling and coordination degree has gone through three stages from 2000 to 2016, namely, the unbalanced development stage from 2000 to 2003, the microbalance stage from 2004 to 2005, and the balanced development stage from 2006 to 2016.

To determine the influence of the evaluation values of two systems on the coupling coordination degree $D$, this paper establishes a multivariate linear regression model that uses the coupling coordination degree $D$ as the explained variable and the evaluation values of the urban public infrastructure system and the urban economic, social, and environmental system as explanatory variables. The model fitting results shown in Tables 16 and 17 are obtained by SPSS software. The fitting results show that the $R^{2}$ fit of the model is 0.995 , which is very close to 1 , indicating that the model has a high degree of fit. The model is shown in Table 17. When the supply level of the urban infrastructure system increases by one unit, the coupling coordination degree $D$ increases by 0.555 . When the demand for the urban economic, social, and environmental system increases by one unit, the coupling coordination degree $D$ increases by 0.244 .

\subsection{Analysis of the Dynamic Coupling Coordination Degree} between the Urban Public Infrastructure System and the Urban Economic, Social, and Environmental System. According to the evaluation value of the supply level of the urban infrastructure system $(f(x))$ and the urban economic, social, and environmental system $(g(y))$ shown in Table 5, we can obtain the evaluation curves and fitting functions of the supply level of the urban infrastructure system $(f(x))$ and the evaluation value of the urban economic, social, and environmental system $(g(y))$. All of these are presented in 
TABLE 15: Degree of coordination between the urban public infrastructure system and urban economic, social, and environmental system.

\begin{tabular}{lccc}
\hline Years & Coordination degree $C$ & Coupling coordination degree $D$ & Coordination level \\
\hline 2000 & 0.9976 & 0.3851 & Mild imbalance development \\
2001 & 0.9983 & 0.4214 & Slightly unbalanced development \\
2002 & 0.9999 & 0.4773 & Slightly unbalanced development \\
2003 & 0.9999 & 0.4943 & Slightly unbalanced development \\
2004 & 0.9961 & 0.5413 & Slightly unbalanced development \\
2005 & 0.9998 & 0.5721 & Slightly unbalanced development \\
2006 & 0.9986 & 0.6478 & Mild imbalance development \\
2007 & 0.9950 & 0.6757 & Mild imbalance development \\
2008 & 0.9922 & 0.6850 & Mild imbalance development \\
2009 & 0.9965 & 0.7128 & Moderately balanced development \\
2010 & 0.9958 & 0.7315 & Moderately balanced development \\
2011 & 1.0000 & 0.7394 & Moderately balanced development \\
2012 & 1.0000 & 0.7458 & Moderately balanced development \\
2013 & 0.9999 & 0.7728 & Moderately balanced development \\
2014 & 0.9995 & 0.8003 & Highly balanced development \\
2015 & 1.0000 & 0.8302 & Highly balanced development \\
2016 & 0.9986 & 0.8200 & Highly balanced development \\
\hline
\end{tabular}

TABLE 16: Summary of multiple linear regression models.

\begin{tabular}{lcccc}
\hline Model & $R$ & $R$ Side & Adjust the $R$ side & Standard estimated error \\
\hline 1 & $0.997^{\mathrm{a}}$ & 0.995 & 0.994 & 0.0111601 \\
\hline
\end{tabular}

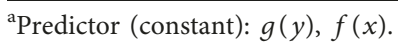

TABLE 17: Multiple linear regression coefficients ${ }^{\mathrm{a}}$.

\begin{tabular}{lcccr}
\hline \multirow{2}{*}{ Model } & Nonstandardized coefficient & \multicolumn{2}{c}{ Standard coefficient } & \multirow{2}{*}{ Sig. } \\
& $B$ & Standard error & Trial version & \\
\hline 1 (constant) & 0.293 & 0.008 & 0.707 & 38.834 \\
$f(x)$ & 0.555 & 0.054 & 0.000 \\
$g(y)$ & 0.244 & 0.057 & 0.299 & 0.000 \\
\hline
\end{tabular}

${ }^{\mathrm{a}}$ Dependent variable: $D$.

Figure 5. The dynamic degree of coupling coordination between the urban public infrastructure system and the urban economic, social, and environmental system is obtained by using equation (16)-18 (Figure 6).

Figure 6 shows that the degree of the dynamic coupling coordination between the urban public infrastructure system and the urban economic, social, and environmental system in Beijing can be divided into three stages. The first phase in 2000 shows that the degree of the dynamic coupling coordination between the two systems is $32.15^{\circ}$ and that the two systems are in the primary coordinated development stage. From 2001 to 2009, the degree of the dynamic coupling coordination between the two systems ranges from $48.96^{\circ}$ to $83.55^{\circ}$; this is the second stage. At this stage, the two systems are in a symbiotic and coordinated development stage. The two systems begin to interact with each other, and the supply level of the urban public infrastructure system increases the demand level of the urban economic, social, and environmental system. Because of the influence of the global financial crisis in 2008, from 2010 to 2016, the degree of the dynamic coupling coordination of two systems changed from $81.77^{\circ}$ to $56.26^{\circ}$, which represents a low level of coexistence and the state of low interaction between the two systems.
3.5. Analysis of the Influencing Factors of the Degree of Coupling between the Urban Public Infrastructure System and the Urban Economic, Social, and Environmental System. The degree of the coupling between the urban public infrastructure system and the urban economic, social, and environmental system is affected by many factors. This paper mainly examines the impact of 20 evaluation indicators of the urban public infrastructure system and 12 evaluation indicators of the urban economic, social, and environmental system. Using SPSS software, a linear regression analysis was performed between coupling degree $D$ and 36 evaluation indicators of the two systems.

As shown in Table 18, the degree of the coupling coordination between the urban infrastructure system and the urban economic, social, and environmental system is most affected by urban sewage treatment capacity. In Table 18, it can be seen that in the 20 indicators in the urban public infrastructure system, the top five influencing factors on the degree of the coupling coordination between two systems are sewage treatment capacity, natural gas ratio, and per capita heating area, total number of urban sanitation special vehicles and equipment, household garbage clearance volume, and bureau number of post and telecommunications. The urban infrastructure system indicators that have a weaker impact on 


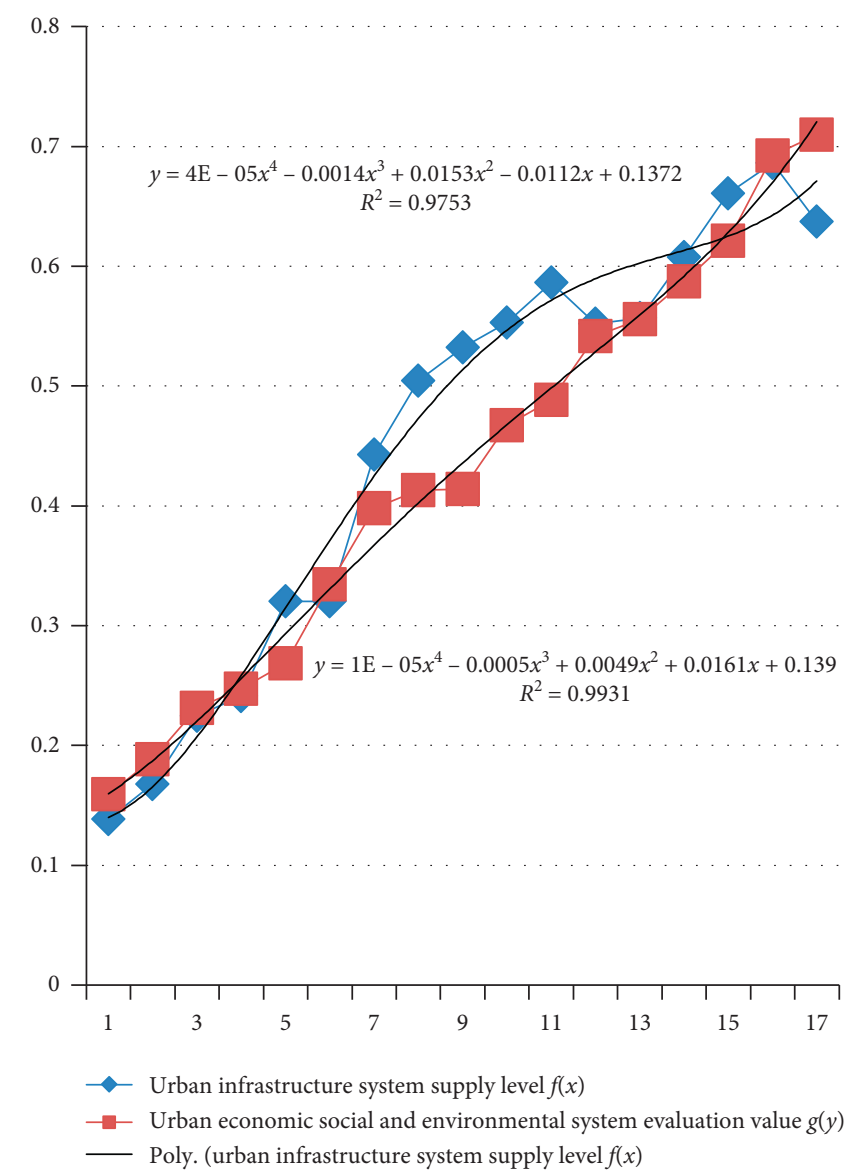

FIgURE 5: Trend function of the Beijing urban infrastructure system and the urban economic, social, and environmental system.

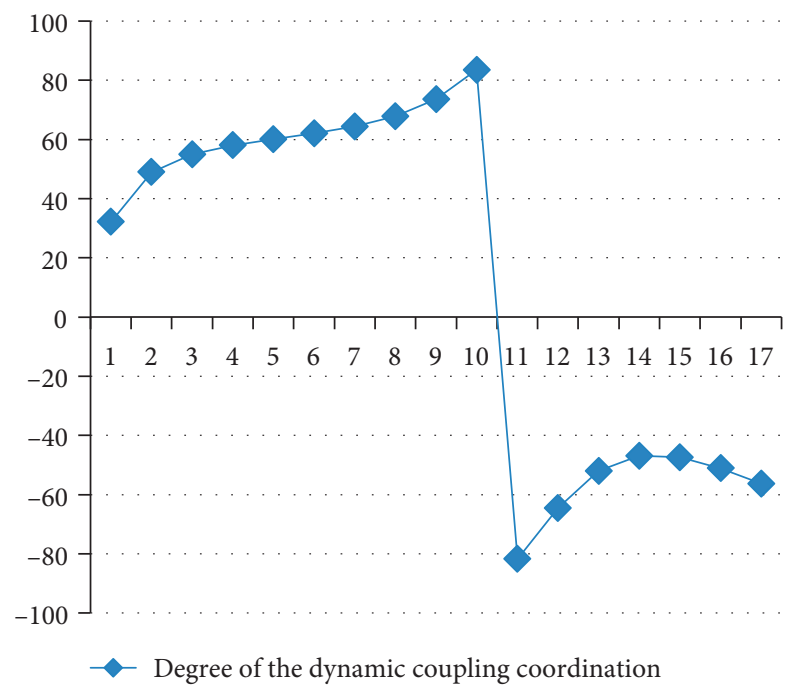

Figure 6: Degree of the dynamic coupling coordination between the urban infrastructure system and the urban economic, social, and environmental system in Beijing.

the degree of coupling coordination between the two systems are mainly railway density and highway facilities, the amount of postal and telecommunications services per capita, and the number of public transportation lines and passenger traffic on public transportation, per capita annual water supply. Table 19 shows that in the urban economic, social, and environmental system, the most influential indicator of the degree of coupling coordination are the regional GDP actual value. The next indicators are three social development indicators: the number of employees in the industry, the per capita household disposable income, and per capita consumption expenditures. The last indicator is actual utilization of foreign direct investment. 
TABLE 18: Impact of the 20 indicators of the urban public infrastructure system on the degree of coupling coordination.

\begin{tabular}{|c|c|c|c|c|}
\hline & Indicator layer & Linear regression equation & $R^{2}$ & Sort \\
\hline \multirow{20}{*}{ Urban public infrastructure system } & $I_{11}:$ per capita social electricity consumption & $Y=0.382+0.432 x$ & 0.807 & 8 \\
\hline & $I_{12}:$ per capita energy consumption & $Y=0.604+0.103 x$ & 0.042 & \\
\hline & $I_{13}:$ natural gas ratio & $Y=0.310+0.468 x$ & 0.896 & 2 \\
\hline & $I_{14}:$ per capita heating area & $Y=0.341+0.468 x$ & 0.942 & 2 \\
\hline & $I_{21}$ : railway road facility density & $Y=0.449+0.329 x$ & 0.911 & 13 \\
\hline & $I_{22}:$ per capita urban road area & $Y=0.524+0.233 x$ & 0.163 & \\
\hline & $I_{23}:$ number of public transportation lines & $Y=0.483+0.361 x$ & 0.686 & 11 \\
\hline & $I_{24}:$ bus operation passenger volume & $Y=0.476+0.361 x$ & 0.789 & 11 \\
\hline & $I_{31}:$ per capita park green area & $Y=0.425+0.390 x$ & 0.941 & 10 \\
\hline & $I_{32}:$ sewage treatment capacity & $Y=0.428+0.534 x$ & 0.862 & 1 \\
\hline & $\begin{array}{c}I_{33}: \text { total number of urban sanitation special vehicle } \\
\text { and equipment }\end{array}$ & $Y=0.406+0.457 x$ & 0.898 & 3 \\
\hline & $I_{34}:$ household garbage clearance volume & $Y=0.439+0.454 x$ & 0.951 & 4 \\
\hline & $I_{41}:$ per capita annual water supply & $Y=0.784-0.441 x$ & 0.943 & 14 \\
\hline & $I_{42}:$ density of water supply pipe & $Y=0.432+0.404 x$ & 0.898 & 9 \\
\hline & $\begin{array}{c}I_{43}: \text { per capita comprehensive water production } \\
\text { capacity }\end{array}$ & $Y=0.821-0.401 x$ & 0.597 & \\
\hline & $I_{44}:$ sewage pipe density & $Y=0.468+0.434 x$ & 0.858 & 7 \\
\hline & $\begin{array}{c}I_{51}: \text { per capita total postal and telecommunications } \\
\text { volume }\end{array}$ & $Y=0.527+0.358 x$ & 0.532 & 12 \\
\hline & $I_{52}:$ mobile phone penetration rate & $Y=0.421+0.442 x$ & 0.841 & 6 \\
\hline & $I_{53}:$ mailine penetration rate & $Y=0.677-0.060 x$ & 0.015 & \\
\hline & $I_{54}$ : bureau number of post and telecommunications & $Y=0.558+0.444 x$ & 0.612 & 5 \\
\hline
\end{tabular}

$Y$ represents the coupling coordination degree $D$, and $x$ represents the corresponding evaluation indicator of urban public infrastructure system in the table.

TABle 19: Influence of 12 indicators of urban economic social and environmental system on coupling coordination degree.

\begin{tabular}{|c|c|c|c|}
\hline Indicator layer & Linear regression equation & $R^{2}$ & Sort \\
\hline$S_{11}:$ regional GDP actual value & $Y=0.425+0.434 x$ & 0.950 & 1 \\
\hline$S_{12}:$ the proportion of the tertiary industry & $Y=0.538+0.288 x$ & 0.241 & \\
\hline$S_{13}$ : actual utilization of foreign direct investment & $Y=0.511+0.402 x$ & 0.779 & 5 \\
\hline$S_{14}:$ fixed assets investment ratio & $Y=0.854-0.365 x$ & 0.669 & 8 \\
\hline$S_{21}$ : per capita household disposable income & $Y=0.498+0.416 x$ & 0.818 & 3 \\
\hline$S_{22}:$ per capita consumption expenditure & $Y=0.504+0.413 x$ & 0.785 & 4 \\
\hline$S_{23}$ : number of employees in three industries & $Y=0.416+0.429 x$ & 0.978 & 2 \\
\hline$S_{24}:$ urbanization rate & $Y=0.411+0.361 x$ & 0.934 & 7 \\
\hline$S_{31}$ : annual average of inhalable particles & $Y=0.858-0.387 x$ & 0.783 & 9 \\
\hline$S_{32}:$ total wastewater discharge & $Y=0.488+0.388 x$ & 0.860 & 6 \\
\hline$S_{33}$ : general industrial solid waste production & $Y=0.808-0.236 x$ & 0.195 & \\
\hline$S_{34}:$ sulfur dioxide emissions & $Y=0.846-0.349 x$ & 0.476 & \\
\hline
\end{tabular}

$Y$ represents the coupling coordination degree $D$, and $x$ represents the corresponding evaluation indicator of the urban economic, social, and environmental system in the table.

\section{Conclusion}

Research on the relationship between the urban public infrastructure system and the urban economic, social, and environmental system is important for the effective management of integrated urban public infrastructure systems and the long-term sustainable development of the city. Taking Beijing as an example, this paper empirically studies the degree of coupling coordination between two system using data from 2000 to 2016. This study finds the following:

(1) From 2000 to 2016, the comprehensive evaluation value of Beijing's urban public infrastructure system and the urban economic, social, and environmental system gradually increased, and the two values are relatively close. From 2006 to 2011, due to the impact of the financial crisis on Beijing's economic development level and the increase of urban infrastructure investment during the Eleventh Five-Year Plan in Beijing, the supply level of Beijing's infrastructure system was higher than that of the urban economic, social, and environmental system. The supply level of urban public infrastructure system was slightly lower than the level of urban economic and social environment development in 2016.

(2) The analysis of the degree of coupling coordination between the Beijing infrastructure system and the urban economic, social, and environmental system shows that it is gradually increasing; the supply level of the urban public infrastructure system has a 
significant impact on the coupling coordination degree of the two systems.

(3) The analysis of the degree of dynamic coupling coordination between the Beijing urban public infrastructure system and the urban economic, social, and environmental system shows that these two systems were in dynamic coupling coordination states from 2000 to 2009 . The global financial crisis affected the degree of dynamic coupling coordination between the two systems, and the two systems entered a low-level symbiotic coupling stage from 2010 to 2016 mainly because the growth rate of urban public infrastructure system supply is negative. This indicates that the dynamic coupling coordination development between two systems can be realized only by accelerating the improvement of urban infrastructure supply in Beijing.

(4) To promote the coupling degree of the two systems in Beijing, the government should give priority to an improvement in the supply level of urban environmental infrastructure, especially an improvement in sewage treatment capacity, the number of urban sanitation special vehicles and equipment, and household garbage clearance volume. Furthermore, improving Beijing's GDP and the social development level, such as the number of employees in three industries in Beijing, has a significant impact on the coupling coordination degree.

On the basis of previous studies, this paper actively discusses the integration and management of urban public infrastructure systems and the coordinated development of urban public infrastructure systems and urban economic, social, and environmental systems. We hope that this research has a positive effect on urban public infrastructure systems by helping them meet their development needs. However, restrictions regarding the availability of relevant statistical data on Beijing affected the evaluation of the supply level of the urban public infrastructure system in Beijing to some extent. This is a problem that should be emphasized in future research.

\section{Data Availability}

The data of this research are from Beijing statistical yearbook 2000-2016, and the data are reliable and available.

\section{Conflicts of Interest}

The authors declare that there are no conflicts of interest regarding the publication of this paper.

\section{Acknowledgments}

The research was supported by the Philosophical Social Science Fund Project in Tianjin (project approval no. TJGL18-034).

\section{References}

[1] OECD (Organisation for Economic Co-Operation and Development), Infrastructure to 2030: Telecom, Land Transport, Water and Electricity, OECD, Parise, France, 2006.

[2] China statistical yearbook, 2017, http://www.stats.gov.cn/tjsj/ ndsj/2017/indexch.htm.

[3] S. M. Rinalidi, J. P. Peerenboom, and T. Kelly, "Identifying, understanding and analyzing critical infrastructure interdependencies," IEEE Control System Magazine, vol. 21, no. 6, pp. 11-25, 2001.

[4] Z. M. Tao and Y. Sun, "Dynamic analysis on influencing factors of urban infrastructure system supply effectiveness: case study of Beijing, China," Research on Financial and Economic Issues, vol. 415, no. 6, pp. 131-137, 2018.

[5] J. W. Hall, R. J. Nicholls, A. J. Hickford et al., Introduction National Infrastructure assessment.the Future of National Infrastructure a System-of-System Approach, Cambridge University Press, Cambridge, UK, 2016.

[6] J. W. Hall, A. Otto, A. J. Hickford et al., A framework for analysing the long-term performance of interdependent infrastructure system. The Future of National Infrastructure a System-of-System Approach, Cambridge University Press, Cambridge, UK, 2016.

[7] A. Otto, J. W. Hall, A. J. Hickford et al., “A quantified systemof-systems modeling framework for robust national infrastructure planning," IEEE Systems Journal, vol. 10, no. 2, pp. 385-396, 2016.

[8] R. Zimmerman and C. E. Restrepo, "The next step: quantifying infrastructure interdependencies to improve security," International Journal of Critical Infrastructures, vol. 2, no. 2/3, pp. 215-230, 2006.

[9] C.-N. Huang, J. J. H. Liou, and Y.-C. Chuang, "A method for exploring the interdependencies and importance of critical infrastructures," Knowledge-Based Systems, vol. 55, no. 5, pp. 66-74, 2014.

[10] P. Zhang and S. Peeta, "Dynamic and disequilibrium analysis of interdependent infrastructure systems," Transportation Research Part B: Methodological, vol. 67, no. 8, pp. 357-381, 2014.

[11] J. Santos-Reyes, D. Padilla-Pérez, and A. N. Beard, "Modeling critical infrastructure interdependency: the case of the Mexico city Metro transport system," Human and Ecological Risk Assessment: An International Journal, vol. 21, no. 5, pp. 1428-1444, 2015.

[12] P. Pederson, D. Dudenhoeffer, S. Hartley et al., Critical Infrastructure Interdependency Modeling: A Survey of U.S. And International Research, Idaho National Laboratory, Idaho Falls, ID, USA, 2006.

[13] C.-L. Chai, X. Liu, W. J. Zhang, and Z. Baber, "Application of social network theory to prioritizing oil \& gas industries protection in a networked critical infrastructure system," Journal of Loss Prevention in the Process Industries, vol. 24, no. 5, pp. 688-694, 2011.

[14] S. Saeid, L. Kattana, P. Jayasinghea et al., "Integrated infrastructure systems-a review," Sustainable Cities and Society, vol. 36, pp. 1-11, 2018.

[15] A. Pereira and J. Andraz, "On the economic effects of public infrastructure investment: a survey of the international evidence," Journal of Economic Development, vol. 38, no. 4, pp. 1-37, 2013.

[16] Z. Elburz, P. Nijkamp, and E. Pels, "Public infrastructure and regional growth: lessons from meta-analysis," Journal of Transport Geography, vol. 58, no. 5, pp. 1-8, 2017. 
[17] I. Yakubu, M. A. Akaateba, and B. A. A. Akanbang, "A study of housing conditions and characteristics in the Tamale Metropolitan Area, Ghana," Habitat International, vol. 44, no. 8, pp. 394-402, 2014.

[18] L. A. Sierra, E. Pellicer, and V. Yepes, "Method for estimating the social sustainability of infrastructure projects," Environmental Impact Assessment Review, vol. 65, no. 7, pp. 41-53, 2017.

[19] A. Schafer and M. Swilling, "Valuing green infrastructure in an urban environment under pressure: the Johannesburg case," Ecological Economics, vol. 86, no. 9, pp. 246-257, 2013.

[20] E. Andersson, S. Barthel, S. Borgström et al., "Reconnecting cities to the Biosphere: stewardship of green infrastructure and urban ecosystem services," $A M B I O$, vol. 43, no. 4, pp. 445-453, 2014.

[21] W. Y. Chen, "The role of urban green infrastructure in offsetting carbon emissions in 35 major Chinese cities: a nationwide estimate," Cities, vol. 44, no. 6, pp. 112-120, 2015.

[22] H. Hall and N. Hickford, "Systems-of-systems analysis of national infrastructure," Engineering Sustainability, vol. 166, no. 5, pp. 249-257, 2016.

[23] J. Y. Zhang, "Research on coordinated development of infrastructure construction investment in Wuhan," Journal of Huazhong University of Science and Technology (Urban Science Edition), vol. 1, pp. 1-5, 2015.

[24] Q. Zhang, "Study on the coordinated development of environmental infrastructure in urban intensive areas in China_- a case study of environmental infrastructure in the pearl river delta urban agglomeration," City Planning, vol. 10, pp. 41-43, 2004.

[25] Y. B. Ji and Y. D. Dou, "New urbanization and coordinated development of transportation infrastructure," Academic Exchange, vol. 268, no. 7, pp. 127-132, 2016.

[26] B. Yu, X. M. Liu, and X. I. Zheng, "Quantitative evaluation and analysis of the coordinated development of urban resources, infrastructure and economic and social development in Qingdao," China Population, Resources and Environment, vol. 4, pp. 149-153, 2007.

[27] J. N. Wu, Y. H. Cao, S. M. Yao et al., "Analysis of the coordinated development of infrastructure and regional economic systems," Economic Geography, vol. 29, no. 10, pp. 1624-1628, 2009.

[28] J. Ying, X. Q. Yao, Y. Cheng et al., "Quantitative analysis of coordination relationship between climate and green infrastructure in Hangzhou city based on coupling model," Chinese Garden, vol. 33, no. 12, pp. 53-57, 2017.

[29] Y. Sun, Z. M. Tao, and P. Yao, "Study on the coordinated development degree of urban public infrastructure composite system," Urban Development Research, vol. 22, no. 5, pp. 24-28, 2015.

[30] Z. M. Tao and Y. Sun, "Study on the utility improvement of urban public infrastructure system from the perspective of supply and demand coordination," Journal of Shenzhen University (Humanities and Social Sciences), vol. 33, no. 3, pp. 100-105, 2016.

[31] L. F. Wang, "Theories and algorithms of network analysis progress (ANP)," System Engineering Theory and Practice, vol. 3, pp. 44-50, 2001.

[32] X. Z. Wu, Nonparametric Statistical Method, Chongqing: Higher Education Press, Chongqing, China, 1996.

[33] D. P. Hou, Introduction to Game Theory, Hefei: University of Science and Technology of China Press, Hefei, China, 2004.

[34] J. H. Yan, C. H. Feng, and L. Li, "Sustainability assessment of machining process based on extension theory and entropy weight approach," Advance Manufacture Technology, vol. 71, pp. 1419-14312014.

[35] F. K. Jesmin and M. B. Sharif, "Weighted entropy for segmentation evaluation," Optics \& Laser Technology, vol. 57, pp. 236-242, 2014.

[36] C. B. Liao, "Quantitative evaluation and classification system of coordinated development of environment and economy-taking the pearl river delta urban agglomeration as an example," Tropical Geography, vol. 2, pp. 76-82, 1999.

[37] X. J. Li and J. G. Tao, "The dynamic coupling analysis for coordinated development of the environment and economy based on cloud model: case study of Henan," in Proceedings of the 2014 International Conference on Management Science \& Engineering, pp. 726-735, IEEE, Helsinki, Finland, August 2014.

[38] C. M. Li and L. Y. Ding, "Evaluation model and application of coordinated development of resource environment and social economy in small towns," Systems Engineering Theory and Practice, vol. 11, pp. 134-139, 2004. 


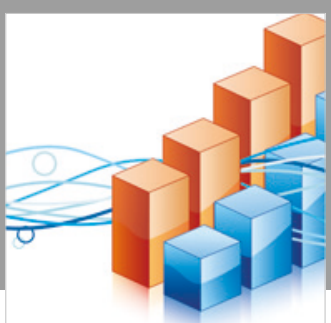

Advances in

Operations Research

\section{-n-m}
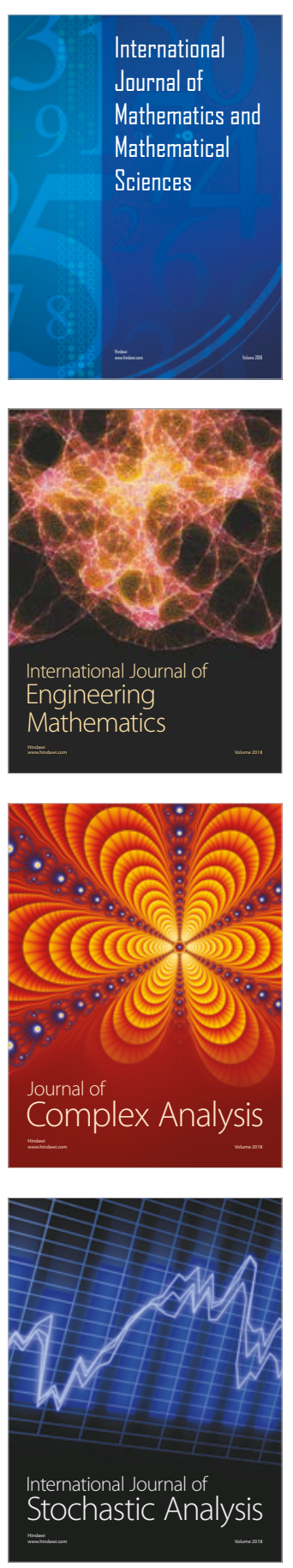
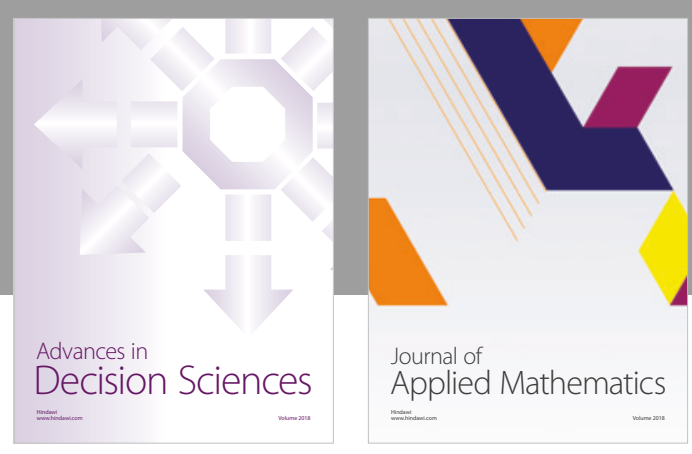

Journal of

Applied Mathematics
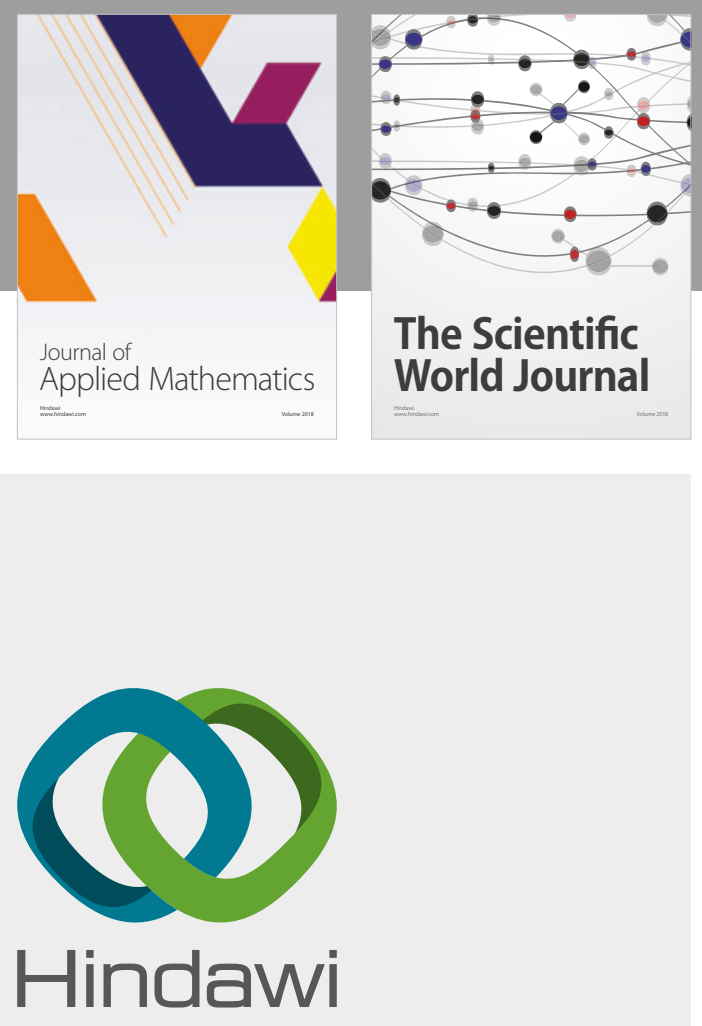

Submit your manuscripts at

www.hindawi.com

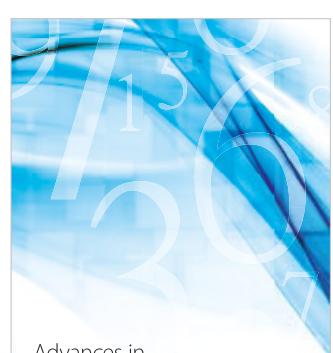

Advances in
Numerical Analysis
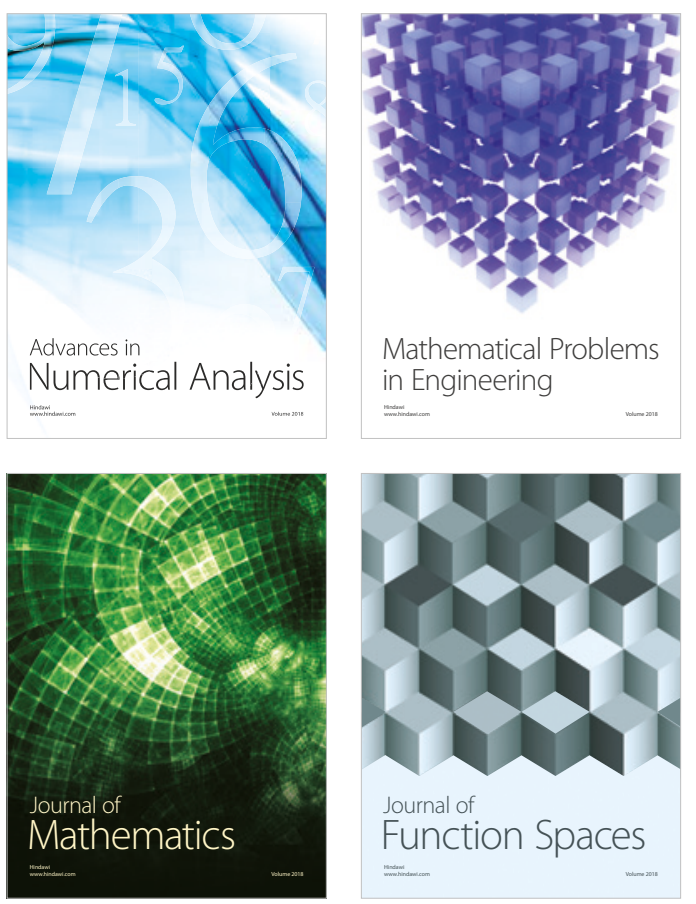

Mathematical Problems in Engineering

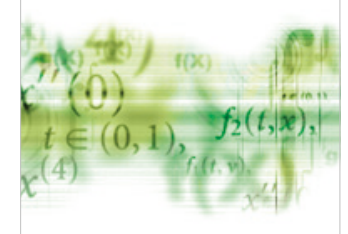

International Journal of

Differential Equations

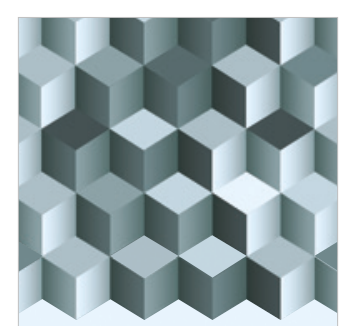

Journal of

Function Spaces

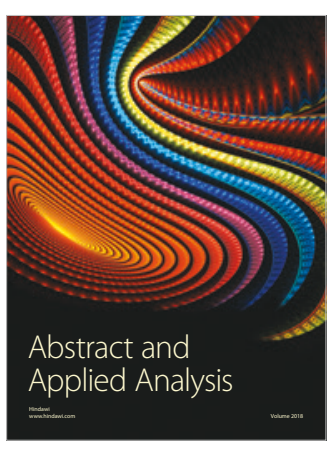

The Scientific

World Journal

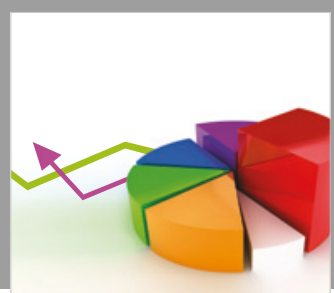

Journal of

Probability and Statistics
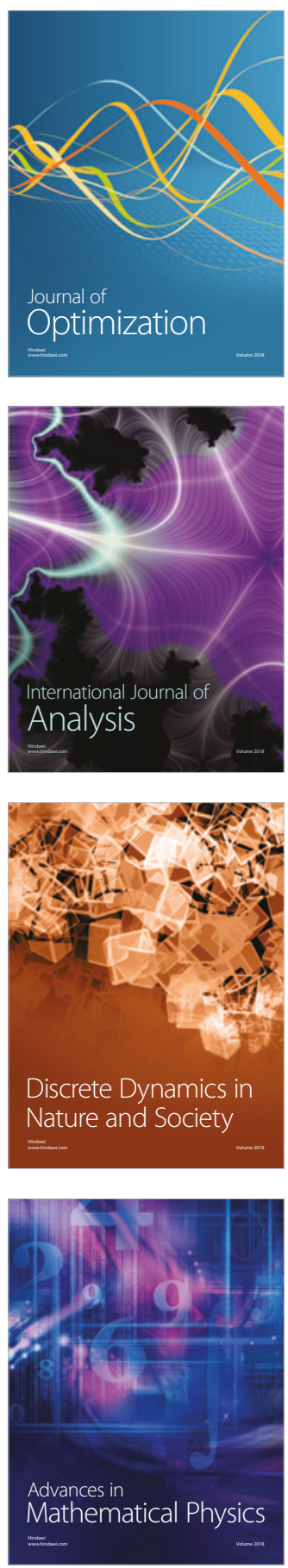